\title{
Therapeutic potency of bee pollen against biochemical autistic features induced through acute and sub-acute neurotoxicity of orally administered propionic acid
}

Huda S. Al-Salem², Ramesa Shafi Bhat ${ }^{1}$, Laila Al-Ayadhi, ${ }^{3,4,5}$ and Afaf El-Ansary ${ }^{1,3,4,6^{*}}$

\begin{abstract}
Background: It is now well documented that postnatal exposure to certain chemicals has been reported to increase the risk of autism spectrum disorder. Propionic acid (PA), as a metabolic product of gut microbiotaandas a commonly used food additive, has been reported to mediate the effects of autism. Results from animal studies may help to identify environmental neurotoxic agents and drugs that can ameliorate neurotoxicity and may thereby aid in the treatment of autism. The present study investigated the ameliorative effects of natural bee pollen against acute and sub-acute brain intoxication induced by (PA) in rats.

Methods: Twenty-four young male Western Albino ratswere enrolled in the present study. They were classified into four equal groups, eachwith6 rats. The control group received only phosphate buffered saline; the oral buffered PA-treated groups (II and III) received a neurotoxic dose of $750 \mathrm{mg} / \mathrm{kg}$ body weight divided in 3 dose of $250 \mathrm{mg} /$ $\mathrm{kg}$ body weight/day serving asthe acute group and $750 \mathrm{mg} / \mathrm{kg}$ body weight divided in 10 equal dose of $75 \mathrm{mg} /$ $\mathrm{kg}$ body weight/day as the sub-acute group. The fourth group received $50 \mathrm{mg}$ bee pollen for 30 days after PA-acute intoxication.

Results: The obtained data showed that the PA-treated groups demonstrated multiple signs of brain toxicity, as indicated by a depletion of serotonin $(5 \mathrm{HT})$, dopamine and nor-adrenaline, together withan increase in IFN- $\gamma$ and caspase 3. Bee pollen was effective in ameliorating the neurotoxic effect of PA. All measured parameters demonstrated minimal alteration in comparison with thecontrol animal than did those of acute and sub-acute PA-treated animals.
\end{abstract}

Conclusions: In conclusion, bee pollen demonstrates anti-inflammatory and anti-apoptotic effects while ameliorating the impaired neurochemistry of PA-intoxicated rats.

Keywords: Autism, Propionic acid, Neurotransmitters, Interferon gamma, Caspase 3, Bee pollen

\section{Background}

A developmental state is the most dominant, host-related factor that affects its response to environmental toxicants. The immature rat brain is morevulnerable toneurotoxic agents than is the adult animal. The single most critical factor of the pattern of damage induced by neurotoxic agents is thetiming of exposure. As later stages

\footnotetext{
* Correspondence: elansary@ksu.edu.sa

${ }^{1}$ Biochemistry Department, Science College, King Saud University, P.O. Box 22452, 11495 Riyadh, Saudi Arabia

${ }^{3}$ Autism Research and Treatment Center, Riyadh, Saudi Arabia

Full list of author information is available at the end of the article
}

of neurodevelopment depend upon the successful completion of early stages, minor disturbances during brain development may cause drastic damage in the future, and neurodevelopmental process are differentially sensitive to specific neurotoxins [1]. Additionally, because different brain regions develop at differenttimes during prenatal and postnatal life, a chemical may produce impairment in different functionaldomains, depending upon the time of exposure [1].

Recently, the behavioral, neuropathological and biochemical abnormalities following exposure to propionic acid (PA) neurodevelopment toxicity were recorded as 
etiological factors of autism. As this short chain fatty acid is used as a food additive and is produced by certain bacterial species that are known as propionibacteria(e.g., Clostridium difficile and Klebsiella pneumonia), it may provide a link between dietary, enterobacterial metabolites, and a genetic predisposition for the subsequent etiology of persistent autistic features in exposed rat pups $[2,3]$.

A growing body of evidence implicateshyperserotonemia, immunological disturbances, oxidative stress and poor detoxification ability together with elevation of proapoptotic markers in the peripheral blood of autistic patients [3-8]. Different animal models have been produced to investigate the environmental contribution, possible causes, and potential treatments of autism. Among the several animal models that have so far been tested, the rat model appears to be an excellent translational system because detailed data are already available on the genetics and behavioral phenotyping of various strains [9]. The etiology ofpersistent autistic features in rat pups were recorded through a panel of biomarkers related to oxidative stress [2,9], neuroinflammation [3], and abnormal neurotransmission [10], together with autistic behavioral changes [11].

Bee pollen is a natural product that is composed of amino acids, lipids, flavinoids, vitamins and micronutrients. It demonstrates antifungal, antimicrobial, anti-inflammatory, and immunostimulating effects $[12,13]$. Pollen is a rich source of fat-soluble vitamins, such as vitamin A, E and D, together with water-soluble vitamins, such as B1, B2, B6, and $\mathrm{C}$. Bee pollen is known to have detoxification activity and can remove heavy metals (e.g., mercury and lead) and drugs (e.g., antibiotics and anti-inflammatory preparations). Pollen also demonstrates anti-inflammatory mechanisms through the inhibition of the activities of cyclooxygenase and lipoxygenase, the enzymes that are responsible for the conversion of arachidonic acid intotoxic compounds as prostaglandin and leukotrienesas inducers of acute and chronic inflammatory conditions in different tissues $[14,15]$.

The recently recorded apitherapeutic mechanism of pollen is attributed to its antimicrobial activity and potency to induce regeneration of damaged tissues [16]. It has also been shown that the ethyl alcohol extract of pollen has antibiotic activity against Grampositive pathogenic bacteria,including Klebsiella pneumonia (A propionobacteria) and Pseudomonas aeurgionsa, and against fungi, such as Candida albicans. Theresponsibility for this activity lies in flavonoids and phenolicacids $[17,18]$. The antioxidant effects of these components are largely related to their free radical scavenging activity. It is the most important components that can treat oxidative stress as an etiological factor and a potential treatment target of autism [19].
This information initiates our interest to test the therapeutic effects of bee pollen on selected biomarkers that are known to be clinically impaired in autistic patients and in a rodent model of autism.

\section{Methods}

The experimental assays for this study were performed on 24 young (approximately 21 days old) male western albino rats $(45$ to $60 \mathrm{~g}$ ). The animals were fed on standard pellet diet, water ad libitum and were maintained in a controlled environment under standard conditions of temperature and humidity with an alternating light- and dark-cycle. Rats were obtained from the animal house of the pharmacy college, King Saud University, and were randomly assigned to four groups of six rats each. The first group consisted of rats to which only phosphate buffered saline was administered and were used as a control group. The second group of rats were given an oral neurotoxic dose (750 mg PA $/ \mathrm{kg}$ body weight over 3 days at a dose of $250 \mathrm{mg}$ PA/kg body weight/day) and served as the acutely treated group. The third group was treated with $750 \mathrm{mg}$ $\mathrm{PA} / \mathrm{kg}$ body weightover 10 days at a dose of $75 \mathrm{mg} \mathrm{PA} / \mathrm{kg}$ body weight/day) and served as the sub-acutely treated group. The fourth group received bee pollen $(50 \mathrm{mg} / \mathrm{kg}$ body weight/day for 30 days) [12]. Bee pollen used in the present study is first elite product, $100 \%$ natural, imported for Wadi Al-Nahilone of the largest marketing company in Saudi Arabia (www.wadialnahil.net). The four groups of rats were housed under controlled temperature $\left(21 \pm 1{ }^{\circ} \mathrm{C}\right)$ with ad libitum access to food and water. The protocol of the present work was approved by the Ethics Committee at the King Saud University, and all experiments were performed in accordance with the guidelines of the National Animal Care and Use Committee.

\section{Tissue preparation}

At the end of the experiment, the rats were anesthetizedwith carbon dioxide and decapitated. The brains were removed from the skull and were dissected into smallpiecesto be homogenized either in distilled water (10 times w/v) (For the assay of IF $\gamma$ and caspase-3) or perchloricacidforthe neurotransmitter assay.

\section{Assay of neurotransmitters (NA, DA and $5 H T$ )}

The concentrations of NA, DA, 5-HT were determined in brain homogenates using high-performance liquid chromatography with electrochemical detection (HPLC-ED) [20]. Brain tissue was homogenized in $150 \mu \mathrm{l} 0.1 \mathrm{M}$ perchloric acid containing $0.4 \mathrm{mM}$ sodium metabisulphiteusingan ultrasonic cell disrupter. Thehomogenates were then centrifuged at $10,000 \mathrm{xg}$ at $4{ }^{\circ} \mathrm{C}$ for $25 \mathrm{~min}$, and the supernatants were filtered through a $0.22 \mathrm{~m}$ filter (Sigma) and frozen at $-70{ }^{\circ} \mathrm{C}$ until analysis. 
Filtrate was injected into the HPLC system, which consisted of a quaternary gradient delivery pump Model HP 1050 (Hewlett-Packard), a sample injector Model 7125 (Rheodyne, Berkeley), and an analytical column ODS 2 C18, $4.6 \times 250 \mathrm{~mm}$ (Hewlett-Packard) that was protected by guard column (Lichnospher $100 \mathrm{RP}-18,4 \times 4 \mathrm{~mm}$ ) with a particle size of $5 \mu \mathrm{m}$ (Hewlett-Packard). The mobile phase was comprised of $0.15 \mathrm{M}$ sodium dihydrogen phosphate, $0.1 \mathrm{mM}$ EDTA, $0.5 \mathrm{mM}$ sodium octanesulphonic acid, $10-12 \%$ methanol (v/v) and $5 \mathrm{mM}$ lithium chloride. The mobile phase was adjusted to $\mathrm{pH} 3.4$ with phosphoric acid, filtered through $0.22 \mathrm{~m}$ filter (Sigma) and degassed with helium. A column temperature of $32{ }^{\circ} \mathrm{C}$ and a flow rate of $1.4 \mathrm{ml} / \mathrm{min}$ were used.

The electrochemical detector model HP 1049 A (Hewlett-Packard) with a glassy carbon workingelectrode was used at a voltage setting of +0.65 Vfor monoamines. The detector response was plotted and measured using a chromate-integrator. The concentration of NA, DA, 5-HT in each sample was calculated from the integrated chromatographic peak area and expressed asng/100 mg wet tissue.

\section{Assay of interferon gamma}

IFNy was measured using an ELISA kit, a product of Thermo Scientific (Rockford, IL, USA), according to the manufacturer's instructions. A polyclonal antibody specific for human IFNywas pre-coated onto a 96-well microplate. IFN $\gamma$ in standards and samples were sandwiched by the immobilized antibody and biotinylated polyclonal antibody specific for IFN $\gamma$, which was then recognized by a streptavidin-peroxidase conjugate. All unbound material was then washed away, and a peroxidase enzyme substrate was added. The color development is stopped, and the intensity of the color is measured at $550 \mathrm{~nm}$ and subtracted from absorbance at $450 \mathrm{~nm}$. The minimum level of IFNy detected by this product is less than $2 \mathrm{pg} / \mathrm{ml}$.

\section{Assay of Caspase3}

Caspase 3 was measured using an ELISA kit, a product of Cusabio (Cusabio, Wuhan, China). The microtiter plate provided in this kit was pre-coated with an antibody specific for caspase3. Standards or samples were then added to the appropriate microtiter plate wells with a biotinconjugated antibody preparation specific for caspase3. After that, avidin conjugated to horseradish peroxidase (HRP) was added to each microplate well and incubated. A TMB (3, 3', 5, 5'tetramethyl-benzidine) substrate solution was then added to each well. Only the wells that contained caspase3, biotin-conjugated antibody, and enzyme-conjugated avidin would exhibit a change in color. The enzyme-substrate reaction was terminated by the addition of a sulfuric acid solution, and color change was measured spectrophotometrically at a wavelength of
$450 \mathrm{~nm} \pm 2 \mathrm{~nm}$. The concentration of caspase 3 in the samples was then determined by comparing the optical density (O.D.) of the samples withthe standard curve.

\section{Statistical analysis}

The data were analyzed using the statistical package for the social sciences (SPSS, Chicago, IL, USA). The results were expressed as the mean \pm S.D. All statistical comparisons between the control and PA and pollen-treated rat groups were performed using a one-way analysis of variance (ANOVA) test complemented with the Dunnett test for multiple comparisons. Significance was assigned at the level of $P<0.05$. A receiver operating characteristics curve (ROC) analysis was performed. The area under the curve (AUC), cutoff values, and degree of specificity and sensitivity were calculated. The area under the curve (AUC) provides a useful metric for comparing different biomarkers, whereas an AUC value close to 1 indicates an excellent predictive marker, a curve that lies close to the diagonal (AUC $=0.5$ ) has no diagnostic utility. An AUC close to 1 is always accompanied by satisfactory values of specificity and sensitivity of the biomarker. Pearson's correlations were performed between the measured parameters.

\section{Results}

The brain homogenates levelsof IF $\gamma$, nor-adrenaline, $5 \mathrm{HT}$, dopamine and caspase- 3 in addition to their percentage change relative to control of all the tested groups,are presented in Table 1. As revealed in Fig. 1, the acute PA-treated group exhibited a significant increase of IFY (148.6\%) and caspase-3 (119.7\%), with a concomitant decrease of the three measured neurotransmitters, NA (66.1\%), DA (64.8\%) and 5HT (61.00\%), in comparison with thecontrol. Likewise, the treatment with a subacute dose of PA in group III significantly increased IF $\gamma(123.9 \%)$ and caspase-3 (119.7 \%),with a drastic decrease in NA (58.5 \%), DA (52.9\%) and 5HT (50.1 \%)in comparison withthe control group. Comparison between group II and group III showed thatsuba-cute mode of treatment provedto be more neurotoxin than acute one. (Table 1). The brain homogenate of bee pollen treated animals also showed improvement in all the tested parameters as shown in Table 1.

Regarding the Pearson's correlations between the measured parameters, Table 2 and Fig. 2 demonstrate the significantpositive correlations betweenIF $\Upsilon$ and caspase 3 $(R=0.567 ; p=0.004)$, nor-adrenaline and 5HT $(R=0.817$; $p=0.001)$, nor-adrenaline and dopamine $(R=0.864$; $p=0.0015)$ and 5HT and dopamine $(R=0.935 ; p=0.001)$. IF $\Upsilon$ was significantly associated with nor-adrenaline $(R=-0.665 ; p=0.001), 5 \mathrm{HT}(R=-0.582 ; p=0.003)$ and dopamine $(R=-0.604 ; p=0.002)$. There was also a significant negative correlation between $5 \mathrm{HT} \sim$ caspase 3 
Table 1 The mean \pm S.D and percentage changes of the four measured parameters in brain homogenates of PPA-acute and sub-acuteintoxicated rats and pollen-treated rats in comparisonwiththecontrol animals

\begin{tabular}{|c|c|c|c|c|c|c|}
\hline Parameter & Group & $\mathrm{N}$ & Mean \pm S.D. & Percent change & $P$ value* & $P$ value ${ }^{* *}$ \\
\hline \multirow[t]{4}{*}{$\mathrm{IF} \Upsilon(\mathrm{pg} / 100 \mathrm{mg})$} & Control & 6 & $82.82 \pm 7.52$ & 100.00 & & \\
\hline & PPA-acute & 6 & $123.05 \pm 6.58$ & 148.57 & 0.001 & \\
\hline & PPA-sub-acute & 6 & $102.60 \pm 5.08$ & 123.87 & 0.001 & 0.001 \\
\hline & Pollen & 6 & $87.40 \pm 2.09$ & 105.52 & 0.203 & 0.001 \\
\hline \multirow[t]{4}{*}{ Nor-adrenaline (ng/100 mg) } & Control & 6 & $4.92 \pm 0.61$ & 100.00 & & \\
\hline & PPA-acute & 6 & $3.25 \pm 0.36$ & 66.12 & 0.001 & \\
\hline & PPA-sub-acute & 6 & $2.88 \pm 0.32$ & 58.49 & 0.001 & 0.086 \\
\hline & Pollen & 6 & $3.79 \pm 0.15$ & 77.18 & 0.005 & 0.013 \\
\hline \multirow[t]{4}{*}{ 5-HT (ng/100 mg) } & Control & 6 & $6.20 \pm 0.78$ & 100.00 & & \\
\hline & PPA-acute & 6 & $3.78 \pm 0.56$ & 61.00 & 0.001 & \\
\hline & PPA-sub-acute & 6 & $3.11 \pm 0.18$ & 50.07 & 0.001 & 0.029 \\
\hline & Pollen & 6 & $4.36 \pm 0.42$ & 70.36 & 0.005 & 0.069 \\
\hline \multirow[t]{4}{*}{ Dopamine (ng/100 mg) } & Control & 6 & $21.12 \pm 2.72$ & 100.00 & & \\
\hline & PPA-acute & 6 & $13.69 \pm 0.80$ & 64.81 & 0.001 & \\
\hline & PPA-sub-acute & 6 & $11.17 \pm 1.29$ & 52.92 & 0.001 & 0.002 \\
\hline & Pollen & 6 & $16.09 \pm 0.71$ & 76.20 & 0.005 & 0.001 \\
\hline \multirow[t]{4}{*}{ Caspase 3 (u/100 mg) } & Control & 6 & $112.66 \pm 4.20$ & 100.00 & & \\
\hline & PPA-acute & 6 & $134.79 \pm 3.27$ & 119.65 & 0.001 & \\
\hline & PPA-sub-acute & 6 & $152.57 \pm 8.97$ & 135.43 & 0.001 & 0.003 \\
\hline & Pollen & 6 & $124.23 \pm 2.89$ & 110.28 & 0.001 & 0.001 \\
\hline
\end{tabular}

*P value between control group and other groups

**P value between PPA-acute group and other groups

$(R=-0.870 ; P=0.001)$ and dopamine $\sim$ caspase $3(R=$ $-0.870 ; P=0.001)$.

Receiver operating characteristics curves are collectively presented as curve A, B and C in Fig. 3. Area under the curve (AUC), cutoff values, sensitivity and specificity are listed in Table 3.

\section{Discussion}

Different animals can be used for acute and sub-acute testing of toxicity, but they may vary with respect to the route of toxin administration. For oral administration, the preferred rodent species is the albino rat (Wistar), and the test substance is usually given in a single dose by gavage [21].

Table 1 demonstrates the acute and sub-acute toxic effects of PA together with the therapeutic potency of bee pollen. Elevated IFN- $\gamma$ can easily show the neurotoxic effect of PA [22]. It was shown that IFN- $\gamma$-activated astrocytes become neurotoxic through the activation of STAT 3 signal transducer, and so STAT3 inhibitors may

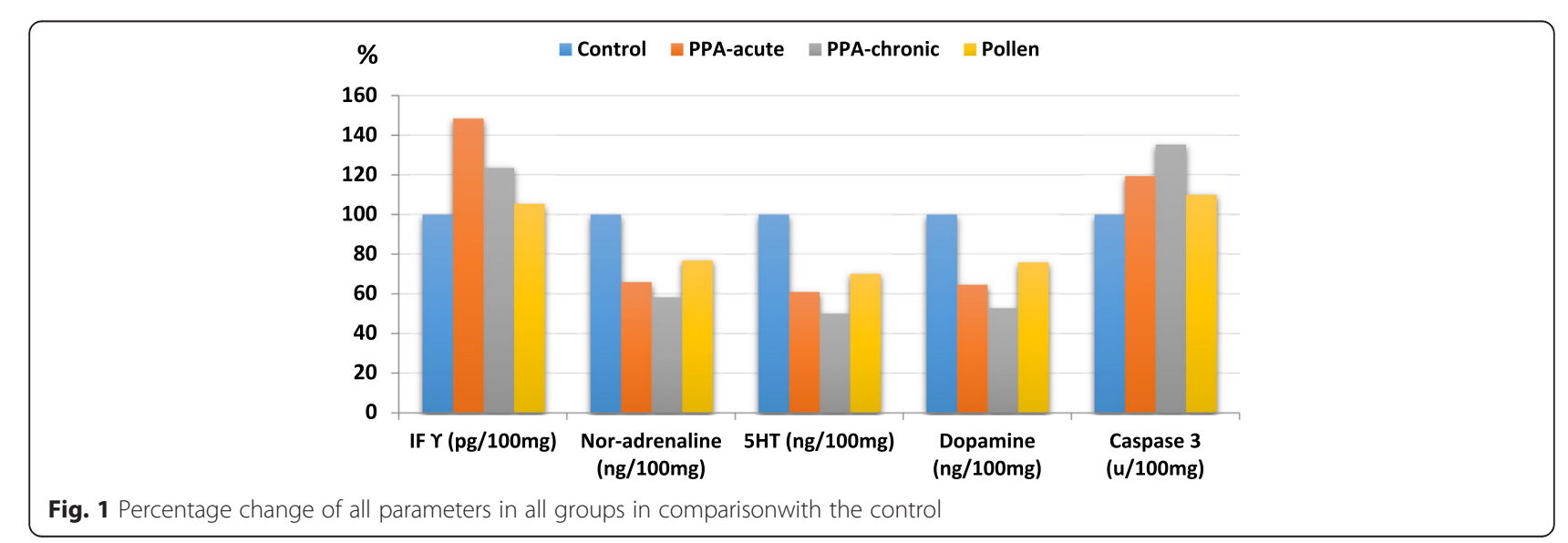


Table 2 Pearson correlations between the measured parameters

\begin{tabular}{llll}
\hline Parameters & R (Person correlation) & Sig. & \\
\hline IFY Nor-adrenaline & $-0.665^{c}$ & 0.001 & $\mathrm{~N}^{b}$ \\
IFY 5-HT & $-0.582^{c}$ & 0.003 & $\mathrm{~N}^{b}$ \\
IFY Dopamine & $-0.604^{c}$ & 0.002 & $\mathrm{~N}^{\mathrm{b}}$ \\
IFY $\sim$ Caspase 3 & $0.567^{c}$ & 0.004 & $\mathrm{P}^{\mathrm{a}}$ \\
Nor-adrenaline $\sim$ 5-HT & $0.817^{c}$ & 0.001 & $\mathrm{P}^{\mathrm{a}}$ \\
Nor-adrenaline Dopamine & $0.864^{c}$ & 0.001 & $\mathrm{P}^{\mathrm{a}}$ \\
Nor-adrenaline $\sim$ Caspase 3 & $-0.781^{c}$ & 0.001 & $\mathrm{~N}^{\mathrm{b}}$ \\
5-HT $\sim$ Dopamine & $0.935^{c}$ & 0.001 & $\mathrm{P}^{\mathrm{a}}$ \\
5-HT $\sim$ Caspase 3 & $-0.850^{c}$ & 0.001 & $\mathrm{~N}^{\mathrm{b}}$ \\
Dopamine $\sim$ Caspase 3 & $-0.870^{c}$ & 0.001 & $\mathrm{~N}^{\mathrm{b}}$ \\
\hline
\end{tabular}

Positive Correlation

${ }^{\mathrm{b}}$ Negative Correlation

${ }^{c}$ Correlation is significant at the 0.01 level

have an anti-neurotoxic effect. Based upon this mechanism, the therapeutic effect of bee pollen, presented in Table 1, demonstrated a non-significant difference between pollen-treated group and control animals $(P<0.203)$, which can be explained by its specific inhibitory mechanism ofangiogenic processes, among which is STAT3 inhibition. Moreover, it can be related to the anti-inflammatory effect of bee pollen. Flavonoids, as major components of pollen, are efficient in decreasing the expression of the inflammatory signaling pathway. This always helps to inhibit the excessive release of nitric oxide and COX-2 expression through the prevention of NF-kBactivation [23-25]. This can be supported by the fact that NO, COX- 2 and NF-kB activation are all recorded as etiological mechanisms related to autism [26-28]. Elevated IFN- $\gamma$ can be related to the recorded $5 \mathrm{HT}$ depletion as a neurotransmitter known to be depleted in a PA-induced rodent model of autism [3]. IFN- $\gamma$ induces indoleamine 2,3-dioxygenase as an enzyme that catalyzes the breakdown of tryptophan, resulting in serotonin depletion [29].

It was generally believed that while brain function is associated with hunger or satiety changes, its functionis independent of metabolic changes associated with food consumption. However, in 1971, Fernstrom and Wurtman [30] proved that under certain conditions, the protein-tocarbohydrate ratio of a meal could affect the concentration of a particularbrain neurotransmitter. For example, the brain turnover of two catecholamine neurotransmitters, dopamine and norepinephrine, can be greatly affected by ingestion of their amino acid precursor, tyrosine, when neurons that release these monoamines are firing frequently. In addition, serotonin, a neurotransmitter involved in the regulation of a variety of brain functions, such as sleeping, pain sensitivity, aggression, and patterns of nutrient selection, have also been shown to be affected by dietary constituents, which are given either as ordinary foods or in purified supplement. Based upon this,it can be suggested that neurotransmitters could be affected by precursor availability or other peripheral factors that are governed by food consumption [31].

Table 1 demonstrates theneurotoxic effect of PA altering the level of DA, 5HT, and NA. Moreover, the therapeutic effect of bee pollen was clear as it ameliorated the recorded neurotoxic effect of PA, thereby demonstrating less significant differencesin comparisonwiththe control. This effect can be attributed to the nutritional fact that pollen contains $22.7 \%$ of protein on average, including $10.4 \%$ of essential amino acids,among which is phenylalanine (precursor of tyrosine) and tryptophan. Bee pollen contains $0.69 \pm 0.003 \%$ and $2.693 \pm 0.476 \%$ of free and total tryptophan, respectively [32]. The reported ameliorating effect of pollen can be attributed to its tryptophan content, as clinical evidence indicates that social impairment, as a core symptom in autism, is related to inadequate brain 5- $\mathrm{HT}$ stores $[33,34]$ and thattryptophandepletionworsens autism symptoms. This can also be supported by reports from parents that their autistic children consume less tryptophan than do their peers. A recent study by Zhang et al. [35] demonstrates that mouse sociability is reduced by acute tryptophan depletion and can be enhanced by tryptophan supplementation.

Apoptosis, as a type of programmed cell death, requires specialized cellular machinery, including a family of cysteine proteases known as caspases [36]. Among these caspases, caspase- 3 is a potent effector of neuronal death during brain development and under certain pathological conditions [37]. Based upon this fact, the neurotoxic effect of PA together with the therapeutic effect of bee pollen can easily be observed in Table 1 and Fig. 4. While acute and sub-acute PA neurotoxicity demonstrated an almost 20 and $35.43 \%$ increase in the concentration of caspase 3 , respectively, bee pollen demonstrated that a reduction in caspase 3 was only $10 \%$ higher in comparisonwiththecontrol. Increase of caspase 3 as a marker of PA neurotoxicity can be related to the elevation of amyloid beta $A \beta$ that was previously reported in the autistic brain. Elevation of amyloid precursor protein (APP) is usually followed by caspase-3 activation, which causes both apoptosis and the proteolytic processing of APP that results in A fformation $[38,39]$. The effect of bee pollen on caspase 3 can be attributed toitsantioxidant effect of flavonoid. It is well documented that flavonoids might protect against apoptosis of hippocampal neurons through suppressing caspasesandthemitochondrial pathway [40].

Based upon the results of the present study, bee pollen can be suggested as a treatment strategy for autistic children that suffer from detoxification deficiencies, demonstrated chronic inflammation and abnormal gut microbiota [41-44]. This suggestion is supported with some recent studies that demonstrated the detoxifying [45], anti- 
A

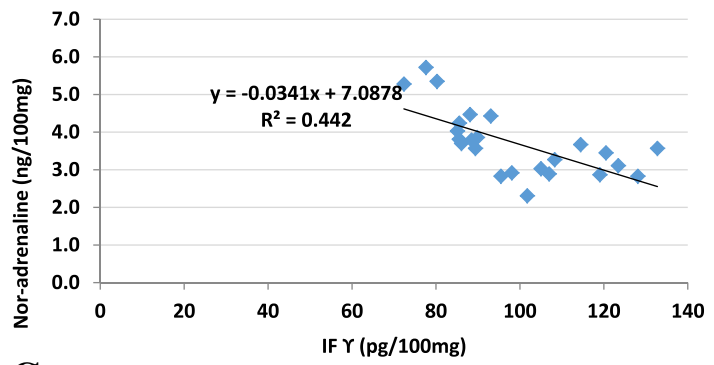

C

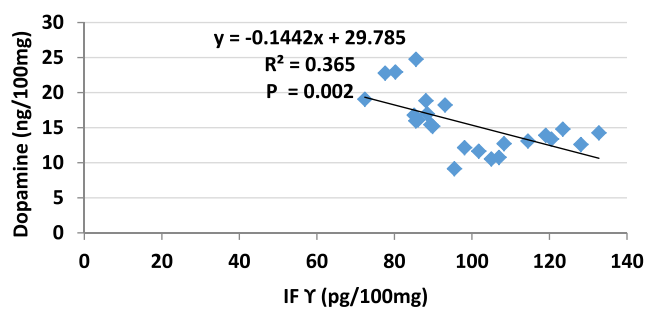

E

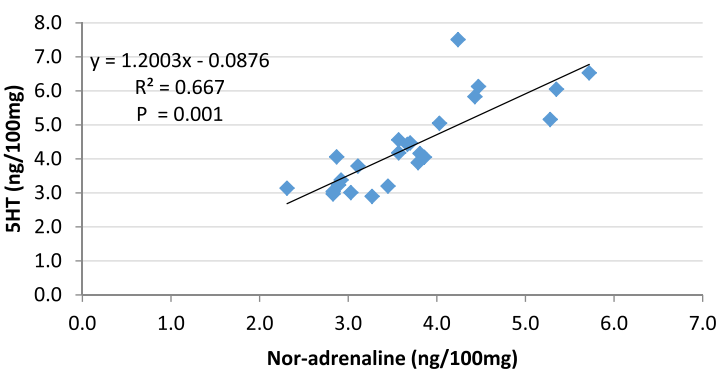

G

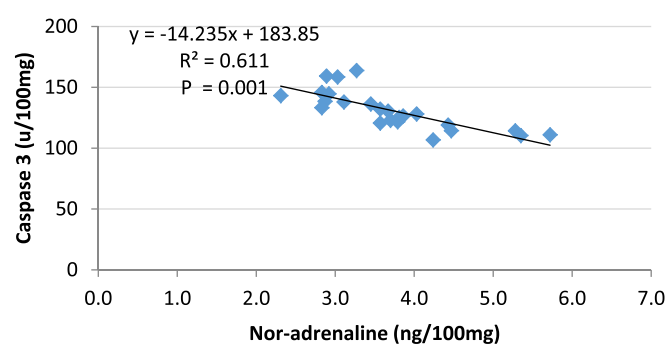

I

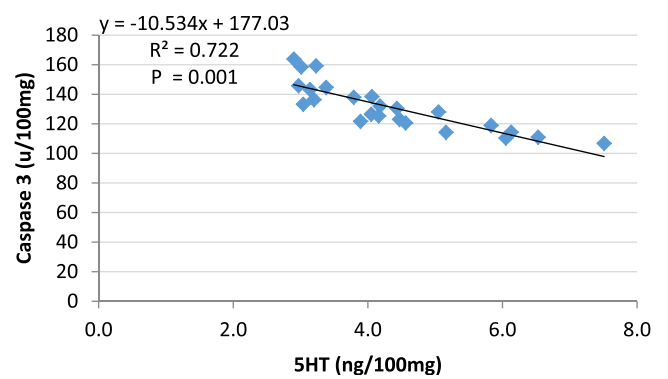

B

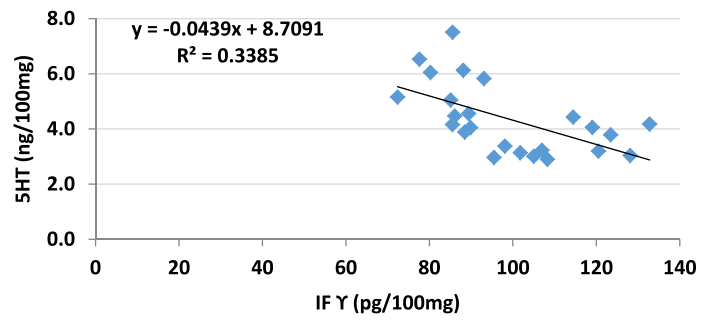

D

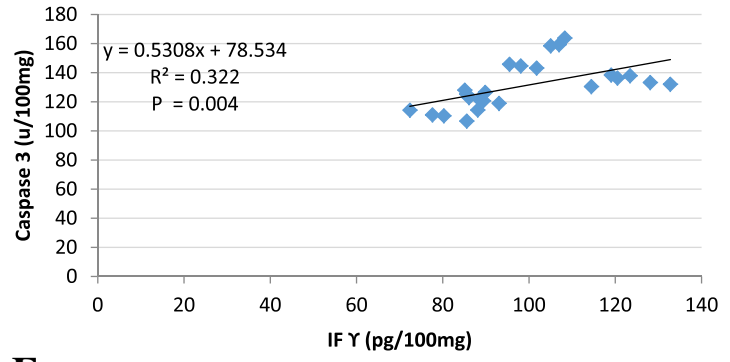

F

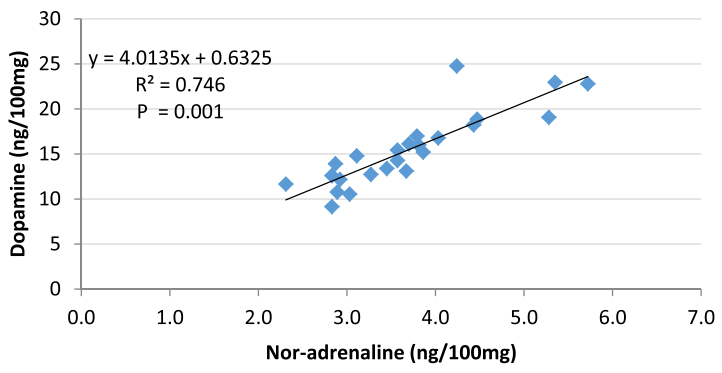

H

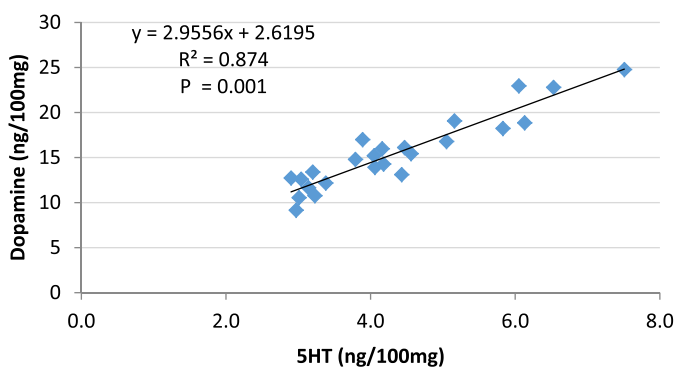

J

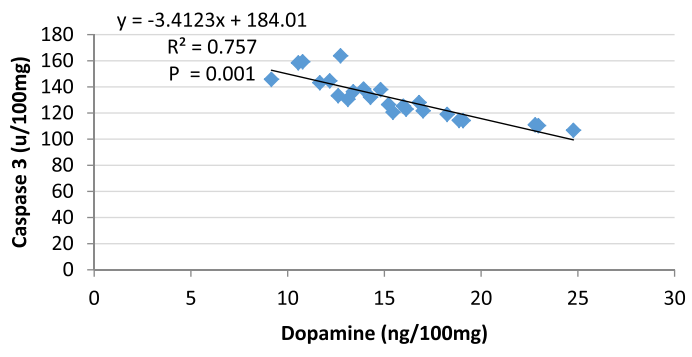

Fig. 2 Pearson's positive and negative correlations with best-fit line curves between the measured parameters. a IF $Y$ and nor-adrenaline (-ve), b IFY and 5-HT (-ve), c IFY and dopamine(-ve), d IFY and caspase 3 (+ve), e nor-adrenaline and 5-HT(+ve), f noradrenaline and dopamine (+ve), $\mathbf{g}$ nor-adrenaline and caspase 3(-ve), h 5-HT and dopamine (+ve), i 5-HT and caspase 3 (- ve), and $\mathbf{j}$ dopamine and caspase 3 (-ve) 


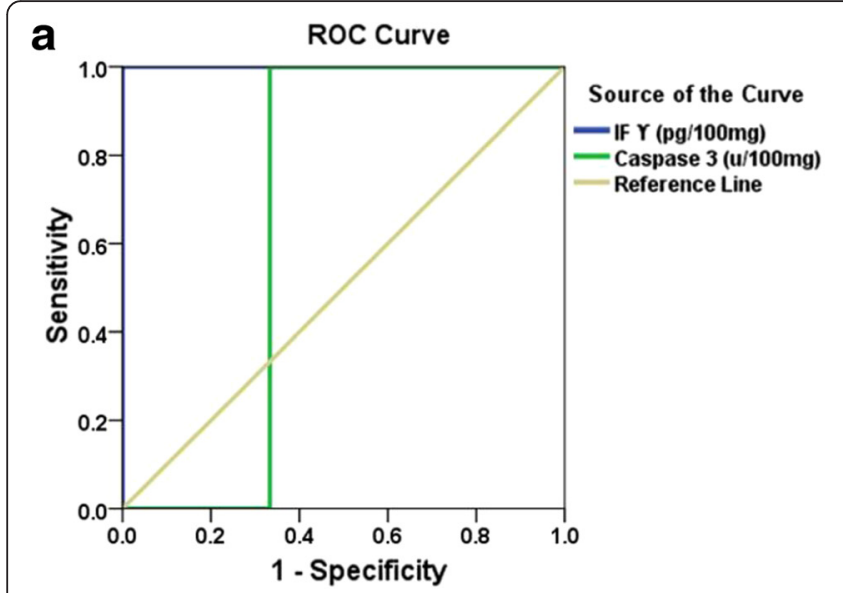

b

ROC Curve

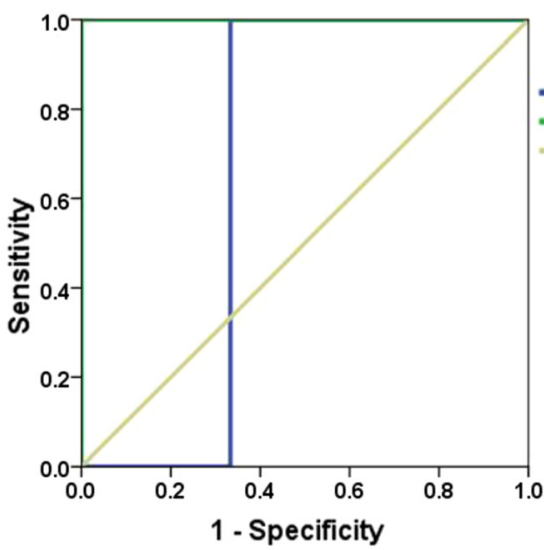

Source of the Curve

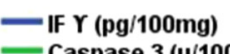
Caspase 3 (u/100mg)

Reference Line

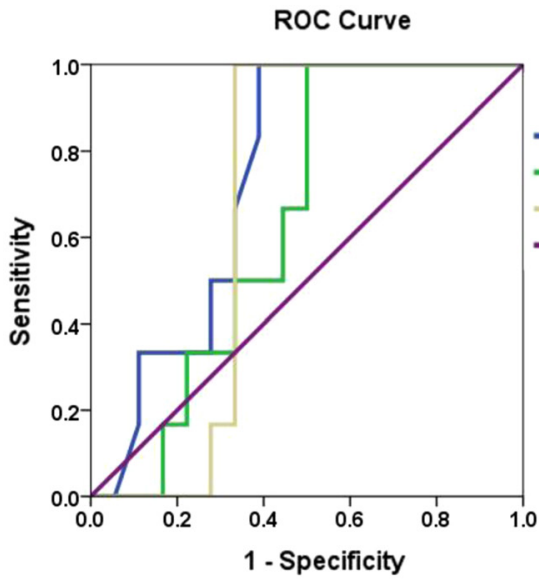

Source of the Curve

Nor-adrenaline (ng/100mg) - $5 \mathrm{HT}$ (ng/100mg)

Dopamine

(ng/100mg)

Reference Line

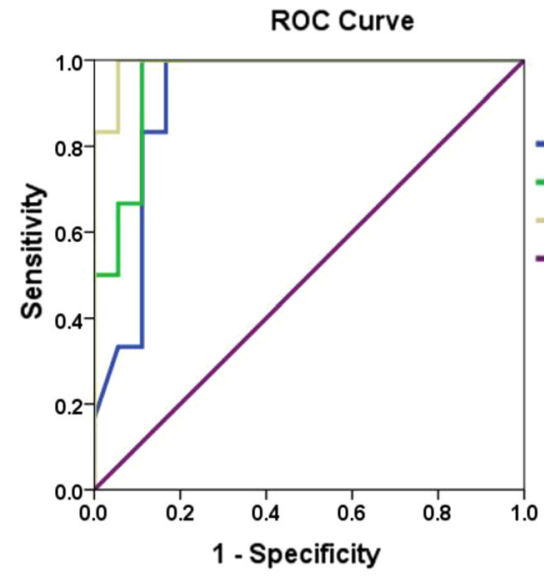

Source of the Curve

Nor-adrenaline (ng/100mg)

- $5 \mathrm{HT}$ (ng/100mg)

Dopamine

(ng/100mg)

Reference Line

C

RoC Curve

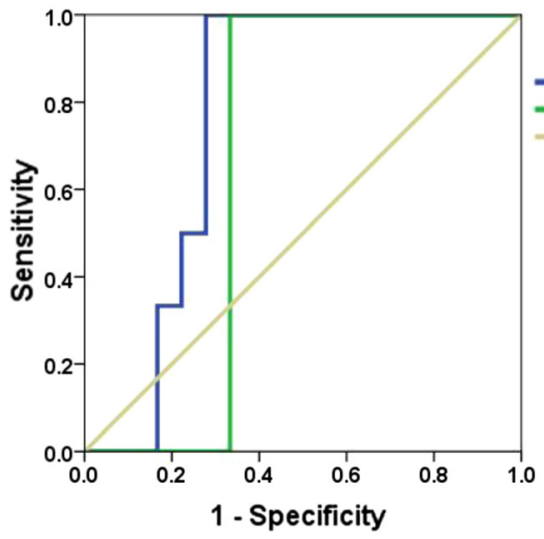

Source of the Curve

一IF $Y(p g / 100 \mathrm{mg})$ Caspase 3 (u/100mg) Reference Line

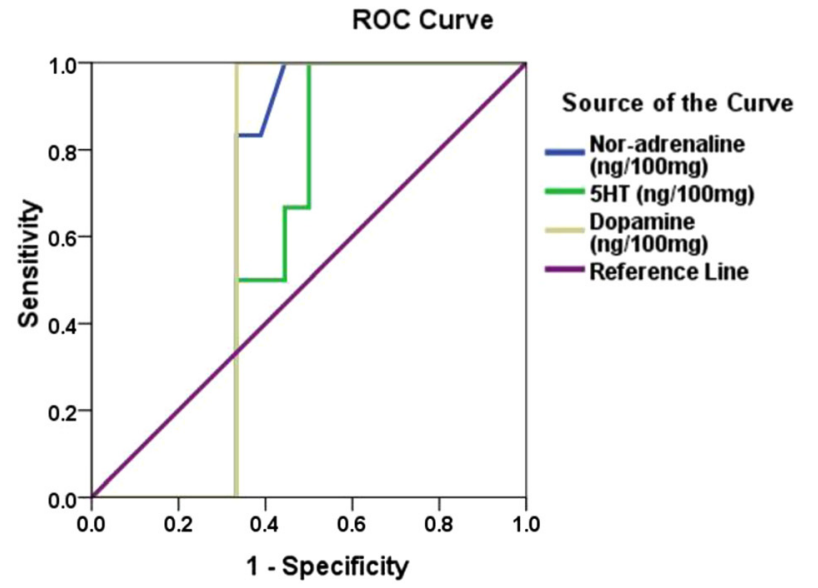

Fig. 3 ROC Curve of $\mathbf{a}$ all parameters in the PPA-acute group, $\mathbf{b}$ all parameters in the PPA-sub-acute group, and $\mathbf{c}$ all parameters in the pollen group

inflammatory [46, 47], and anti-microbial effects of bee pollen $[13,17,18]$.

Table 2 and Fig. 1 demonstrate the positive correlations between the three measured neurotransmitters (5HT, dopamine and nor-adrenaline). This can ascertain the impairment of brain neurochemistry by PA and also the therapeutic effects of bee pollen. A positive correlation between IFN- $\gamma$ and caspase 3 demonstrates the role of neuroinflammation in neuronal loss. This can find support in the work of Lopez-Ramirez et al. [48], 
Table 3 ROC curve of the measured parameters in acute, sub-acute and pollen-treated groups in all groups

\begin{tabular}{|c|c|c|c|c|c|}
\hline & Group & Area under the curve & Best Cutoff value & Sensitivity \% & Specificity \% \\
\hline \multirow[t]{3}{*}{ IFY (pg/100 mg) } & PPA-acute & 1.000 & 111.370 & $100.0 \%$ & $100.0 \%$ \\
\hline & PPA- sub-acute & 0.667 & 94.260 & $100.0 \%$ & $66.7 \%$ \\
\hline & Pollen & 0.769 & 91.450 & $100.0 \%$ & $72.2 \%$ \\
\hline \multirow[t]{3}{*}{ Nor-adrenaline (ng/100 mg) } & PPA-acute & 0.741 & 3.685 & $100.0 \%$ & $61.1 \%$ \\
\hline & PPA- sub-acute & 0.912 & 3.360 & $100.0 \%$ & $83.3 \%$ \\
\hline & Pollen & 0.653 & 3.510 & $100.0 \%$ & $55.6 \%$ \\
\hline \multirow[t]{3}{*}{ 5-HT (ng/100 mg) } & PPA-acute & 0.639 & 4.450 & $100.0 \%$ & $50.0 \%$ \\
\hline & PPA- sub-acute & 0.954 & 3.585 & $100.0 \%$ & $88.9 \%$ \\
\hline & Pollen & 0.593 & 3.840 & $100.0 \%$ & $50.0 \%$ \\
\hline \multirow[t]{3}{*}{ Dopamine (ng/100 mg) } & PPA-acute & 0.676 & 15.005 & $100.0 \%$ & $66.7 \%$ \\
\hline & PPA- sub-acute & 0.991 & 12.920 & $100.0 \%$ & $94.4 \%$ \\
\hline & Pollen & 0.667 & 15.005 & $100.0 \%$ & $66.7 \%$ \\
\hline \multirow[t]{3}{*}{ Caspase 3 (u/100 mg) } & PPA-acute & 0.667 & 129.310 & $100.0 \%$ & $66.7 \%$ \\
\hline & PPA- sub-acute & 1.000 & 140.835 & $100.0 \%$ & $100.0 \%$ \\
\hline & Pollen & 0.667 & 129.310 & $100.0 \%$ & $66.7 \%$ \\
\hline
\end{tabular}

which proves that high TNF- $\alpha$ and IFN- $\gamma$ levels were associated with caspase-3/7 activation, which is directly related to blood-brain barrier damage through the alteration of the phenotype and function of brain endothelial cells. Conversely, negative correlations between the impaired neurotransmitters and bothIFN- $\gamma$ and caspase 3 suggest that amelioration of neurotransmitters through the availability of their amino acids precursors (e.g., tyrosine and tryptophan) in bee pollen can help to reduce the elevated concentrations of IFN- $\gamma$ and caspase- 3 as markers of neuroinflammation and apoptosis, respectively.
Table 3 and Fig. 2 demonstrate the area under the curve (AUC), specificity and sensitivity of the measured parameters in acute and sub-acute PA intoxicated rats together with bee pollen-treated animals. Asall measured parameters recorded satisfactory values of AUC, sensitivity and specificityserve as markers for sub-acute PA neurotoxicity and as less predictive values for the ameliorating effects of bee pollen (AUC range of 0.6-0.769), while IFY is suggested to be a good marker for acute PA toxicity given that the AUC is equal to 1 and that it is $100 \%$ specific and sensitive [49].

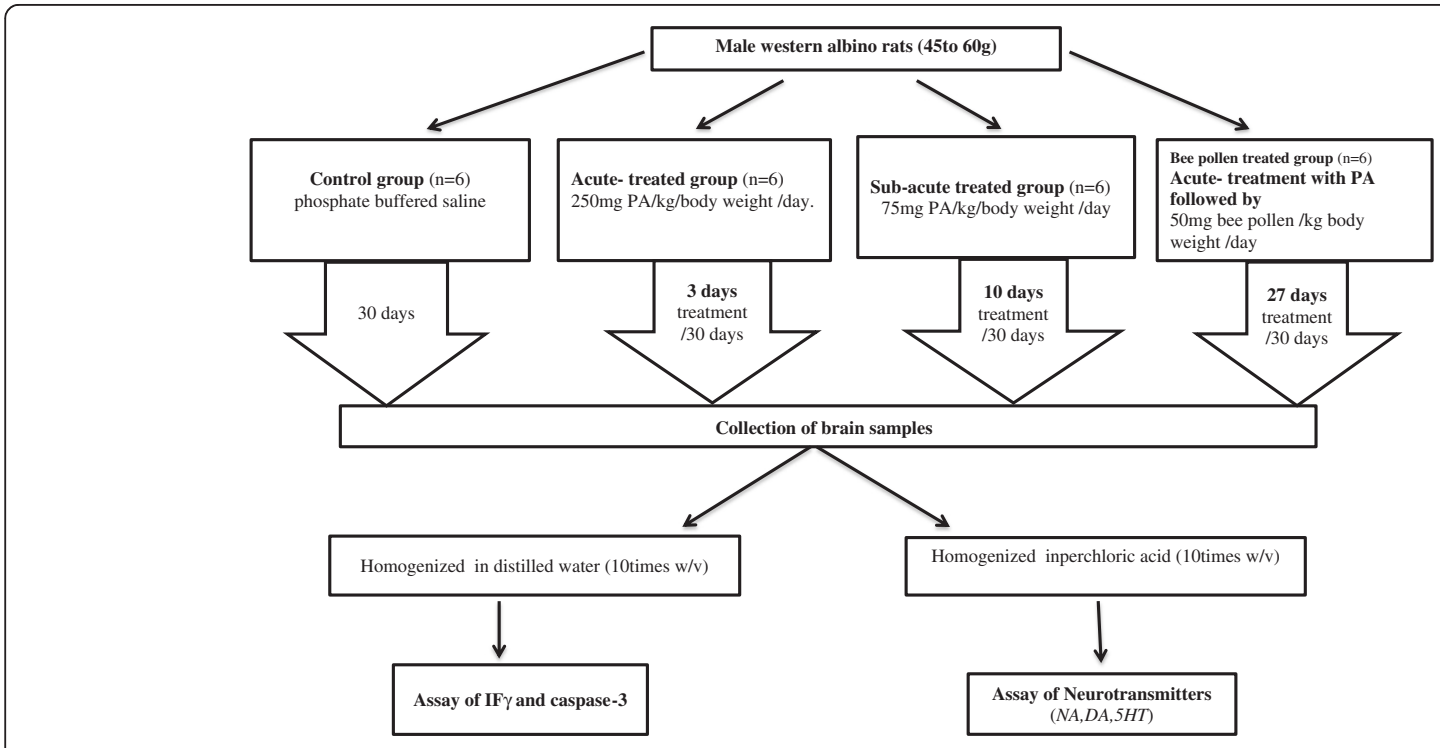

Fig. 4 Schematic presentation of the experimental work demonstrating treatment of different studied groups 


\section{Conclusion}

Acute and sub-acute orally administered propionic acid resulted in changes in biochemical parameters. The alteration of neurotransmitters, cytokines and pro-apoptotic markers observed can be related to oxidative stress induced by PA. Bee pollen, due to the biological properties of its components (in particular, phenolic compounds and amino acid composition), has been determined to exhibit strong free radical scavenging and antioxidant activity. Therefore, it has been concluded that bee pollen can be used safely to ameliorate oxidative stress, neuroinflammation, poor detoxification, and abnormal gut microbiota as mechanisms involved in the etiology of autistic features.

\section{Ethics approval and consent to participate}

Present work was approved by the Ethics Committee at the King Saud University, and all experiments were performed in accordance with the guidelines of the National Animal Care and Use Committee.

\section{Consent for publication \\ Not applicable.}

\section{Availability of data and materials}

The datasets supporting the conclusions of this article are presented in this main paper. Animals were obtained from the animal house of the pharmacy college, King Saud University.

\section{Abbreviations}

5HT: serotonin; ANOVA: one-way analysis of variance; APP: amyloid precursor protein; AUC: area under the curve; $A \beta$ : amyloid beta; DA: dopamine; EDTA: ethylenediaminetetraacetic acid; HPLC-ED: high-performance liquid chromatography with electrochemical detection; HRP: horseradish peroxidase; IFN- $\gamma$ : interferon gamma; NA: nor-adrenaline; O.D: optical density; PA: propionic acid; $\mathrm{ROC}$ : receiver operating characteristics curve;

S.D: standard deviation; TNF-a: tumor necrosis factor alpha.

\section{Competing interests}

The authors declare that they have no competing interests.

\section{Authors' contributions}

$\mathrm{HA}$ : Suggested the use of bee pollen and revised the manuscript; RB: Performed the practical; LA: Co-drafted the manuscript; AE: Suggested the use of propionic acid for autism modeling, performed the statistical analysis and co-drafted the manuscript. All authors read and approved the final manuscript.

\section{Acknowledgements}

This research project was supported by a grant from the research center of the Center for Female Scientific and Medical Colleges at King Saud University.

\section{Funding}

Research center of the Center for Female Scientific and Medical Colleges at King Saud University

\section{Author details}

'Biochemistry Department, Science College, King Saud University, P.O. Box 22452, 11495 Riyadh, Saudi Arabia. ${ }^{2}$ Department of Pharmaceutical Chemistry, College of Pharmacy, King Saud University, Riyadh, Saudi Arabia.

${ }^{3}$ Autism Research and Treatment Center, Riyadh, Saudi Arabia. ${ }^{4}$ Shaik
AL-Amodi Autism Research Chair, King Saud University, Riyadh, Saudi Arabia. ${ }^{5}$ Department of Physiology, Faculty of Medicine, King Saud University, Riyadh, Saudi Arabia. ${ }^{6}$ Medicinal Chemistry Department, National Research Centre, Dokki, Cairo, Egypt.

Received: 27 June 2015 Accepted: 16 April 2016

Published online: 23 April 2016

\section{References}

1. Mendola P, Selevan SG, Gutter S, Rice D. Environmental factors associated with a spectrum of neurodevelopmental deficits. Ment Retard Dev Disabil. 2002:8:188-97.

2. MacFabe DF, Cain DP, Rodriguez-Capote K, Franklin AE, Hoffman JE, Boon F, Taylor AR, Kavaliers M, Ossenkopp KP. Neurobiological effects of intraventricular propionic acid in rats: possible role of short chain fatty acids on the pathogenesis and characteristics of autism spectrum disorders. Behav Brain Res. 2007;176(1):149-69.

3. El-Ansary AK, Ben Bacha A, Kotb M. Etiology of autistic features: the persisting neurotoxic effects of propionic acid. J Neuroinflammation. 2012;9.

4. Veenstra-VanderWeele J, Muller $\mathrm{CL}$, Iwamoto $\mathrm{H}$, Sauer JE, Owens WA, Shah CR, Cohen J, Mannangatti P, Jessen T, Thompson BJ, Ye R, Kerr TM, Carneiro AM, Crawley JN, Sanders-Bush E, McMahon DG, Ramamoorthy S, Daws LC, Sutcliffe JS, Blakely RD. Autism gene variant causes hyperserotonemia, serotonin receptor hypersensitivity, social impairment and repetitive behavior. Proc Natl Acad Sci U S A. 2012;109(14):5469-74.

5. Ashwood P, Krakowiak P, Hertz-Picciotto I, Hansen R, Pessah I, Van de Water J. Elevated plasma cytokines in autism spectrum disorders provide evidence of immune dysfunction and are associated with impaired behavioral outcome. Brain Behav Immun. 2011;25:40-5.

6. El-Ansary AK, Ben Bacha AG, Al-Ayadhi LY. Pro-inflammatory and proapoptotic markers in relation to mono and di-cations in plasma of autistic patients from Saudi Arabia. J Neuroinflammation. 2011;8:142.

7. Goines PE, Ashwood P. Cytokine dysregulation in autism spectrum disorders (ASD): possible role of the environment. Neurotoxicol Teratol. 2013;36:67-81.

8. Ricci S, Businaro R, Ippoliti F, Vasco VL, Massoni F, Onofri E, Troili G, Pontecorvi V, Morelli M, Ricciardi MR. Altered cytokine and BDNF levels in Autism spectrum disorder. Neurotoxicity Res. 2013:24:491-501.

9. Shultz SR, MacFabe DF, Ossenkopp KP, Scratch S, Whelan J, Taylor R, Cain DP. Intracerebroventricular injection of propionic acid, an enteric bacterial metabolic end-product, impairs social behavior in the rat: implications for an animal model of autism. Neuropharmacology. 2008;54(6):901-11.

10. Narita N, Kato M, Tazoe M, Miyazaki K, Narita M, Okado N. Increased monoamine concentration in the brain and blood of fetal thalidomideandvalproic acid-exposed rat: putative animal models for autism. Pediatr Res. 2002;52:576.

11. Ossenkopp KP, Kelly A, Foley KA, Gibson J, Fudge MA, Kavaliers M, Cain DP, MacFabe DF. Systemic treatment with the enteric bacterial fermentation product, propionic acid, produces both conditioned taste avoidance and conditioned place avoidance in rats. Behav Brain Res. 2012;227:134.

12. Almaraz-Abarca N, Campos MDG, Ávila-Reyes JA, Naranjo-Jiménez N, Herrera-Corral J, González-Valdez LS. Variability of antioxidant activity among honeybee-collected pollen of different botanical origin. Interciencia. 2004; 29(10):574-8.

13. Kroyer $\mathrm{H}$. Evaluation of bioactive properties of pollen extracts as functional dietary food supplement. Innovative Food Sci Emerg Technol. 2001;2(3): $171-4$.

14. Eraslan G, Kanbur M, Silici S, Liman B, Altinordulu S, Sarica ZS. Evaluation of protective effect of bee pollen against propoxur toxicity in rat. Ecotoxicol Environ Saf. 2009:72(3):931-7.

15. Pascoal A, Rodrigues S, Teixeira A, Feas X, Estev-inho LM. Biological activities of commercial bee pollens: antimicrobial, antimutagenic, antioxidant and anti-inflammatory. Food Chem Toxicol. 2014;63:233-9.

16. Komosinska-Vassev K, Olczyk P, Kaźmierczak J, Mencner L, Olczyk K. Bee pollen: chemical composition and therapeutic application. Evid Based Complement Alternat Med. 2015;2015:297425.

17. Baltrusayt V, Venskmonis PR, Ceksteryte V. Antibacterial activity of honey and beebread of different origin against Saureus and S-epidermidis. Food Technol Biotechnol. 2007:45(2):201-8.

18. Erkmen O, Ozcan MM. Antimicrobial effects of Turkishpropolis pollen, and laurel on spoilage and pathogenic foodrelated microorganisms. J Med Food. 2008;11(3):587-92 
19. Smaga I, Niedzielska E, Gawlik M, Moniczewski A, Krzek J, Przegaliński E, Pera J, Filip M.. Oxidativestress as an etiologicalfactor and a potentialtreatmenttarget of psychiatricdisorders. Part2. Depression, anxiety, schizophrenia and autism. Pharmacol Rep. 2015;67(3):569-80.

20. Zagrodzka J, Romaniuk A, Wieczorek M, Boguszewski P. Bicuculline administration into ventromedial hypothalamus: effects on fear and regional brain monoamines and GABA concentrations in rats. Acta Neurobiol Exp. 2000;60(3):333-43.

21. Theophine CO, Peter AA, Adaobi CE, Maureen OO, Collins AO, Frankline N, et al. Evaluation of the acute and sub-acute toxicity of Annonasenegalensis root bark extracts. Asian Pac J Trop Med. 2012;5:277-82.

22. Hashioka S, Klegeris A, Qing H, McGeer PL. STAT3 inhibitors attenuate interferon- $Y$-induced neurotoxicity and inflammatory molecule production by human astrocytes. Neurobiol Dis. 2011;41(2):299-307.

23. Ha SK, Lee P, Park JA, Oh HR, Lee SY, Park JH, Lee EH, Ryu JH, Lee KR, Kim SY. Apigenin inhibits the production of NO and PGE2 in microglia and inhibits neuronal cell death in a middle cerebral artery occlusion-induced focal ischemia mice model. Neurochem Int. 2008;52(4-5):878-86.

24. Raso GM, Meli R, Di Carlo G, Pacilio M, Di Carlo R. Inhibition of inducible nitric oxide synthase and cyclooxygenase-2 expression by flavonoids in macrophages J774. Life Sci. 2001:496:12-8.

25. Vauzour D, Martinsen A, Layé S. Neuroinflammatory processes in cognitive disorders: Is there a role for flavonoids and n-3 polyunsaturated fatty acids in counteracting their detrimental effects? Neurochem Int. 2015;89:63-74.

26. Young AM, Campbell E, Lynch S, Suckling J, Powis SJ. Aberrant NF-kappaB expression in autism spectrum condition: a mechanism for neuroinflammation. Front Psychiatry. 2011;2:27.

27. Yui K, Imataka G, Nakamura H, Ohara N, Naito Y. Eicosanoids derived from arachidonic acid and their family prostaglandins and cyclooxygenase in psychiatric disorders. CurrNeuropharmacol. 2015;13(6):776-85.

28. Sweeten TL, Posey DJ, Shankar S, Mc Dougle CJ. High nitric oxide production in autistic disorder: a possible role for interferon-gamma. Biol Psychiatry. 2004;55(4):434-7.

29. Mehraj $V$, Routy JP. Tryptophan catabolism in chronic viral infections: handling uninvited guests. Int J Tryptophan Res. 2015;8:41-8.

30. Fernstrom JD, Wurtman RJ. Brain serotonin content: increase following ingestion of carbohydrate diet. Science. 1971;174(4013):1023-5.

31. Wurtman RJ. Nutrients affecting brain composition and behavior. Integr Psychiatry. 1987;5(4):226-38.

32. DetDegrandi-hoffman G, Eckholm BJ, Huang MH. A comparison of bee bread made by Africanized and European honey bees (Apismellifera) and its effects on hemolymph protein titers. Apidologie. 2013;44:52-63.

33. Rubin DH, Althoff RR, Ehli EA, Davies GE, Rettew DC, Crehan ET, Walkup JT, Hudziak JJ. Candidate gene associations with withdrawn behavior. J Child Psychol Psychiatry. 2013;54:1337-45.

34. Yang CJ, Tan HP, Du YJ. The developmental disruptions of serotonin signaling may be involved in autism during early brain development. Neuroscience. 2014;267C:1e10.

35. Zhang WQ, Smolik CM, Barba-Escobedo PA, Gamez M, Sanchez JJ, Javors MA Daws LC, Gould GG. Acute dietary tryptophan manipulation differentially alters social behavior, brain serotonin and plasmacorticosterone in three inbred mouse strains. Neuropharmacology. 2015;90:1-8.

36. Thornberry NA, Lazebnik Y. Caspases: enemies within. Science. 1998;281: 1312-6.

37. Nicholson DW, Ali A, Thornberry NA, Vaillancourt JP, Ding CK, Gallant M, Gareau Y, Griffin PR, Labelle M,Lazebnik YA, Munday NA, Raju SM, Smulson ME, Yamin T, Yu VL, Miller D. Identification and inhibition of the ICE/CED-3 protease necessary for mammalian apoptosis. Nature. 1995;376:37-43.

38. Al-Ayadhi LY, Ben Bacha AG, Kotb M, El-Ansary AK. A novel study on amyloid $\beta$ peptide 40, 42 and 40/42 ratio in Saudi autistics. Behav Brain Funct. 2012;8:4.

39. Frackowiak J, Mazur-Kolecka B, Kuchna I, Nowicki K, Brown WT, Wegiel J. Accumulation of amyloid-beta peptide species in four brain structures in children with autism. San Diego: International Meeting for Autism Research; 2011.

40. Guo M, Suo Y, Gao Q, Du H, WenyunZeng W, Wang Y, Hu X, Jiang X. The protective mechanism of Ginkgolides and Ginkgo flavonoids on the TNF-a induced apoptosis of rat hippocampal neurons and its mechanisms in vitro. Heliyon. 2015;1(1), e00020.

41. Al-Abdali A, Al-Ayadhi L, El-Ansary A. Association of social and cognitive impairment and biomarkers in autism spectrum disorders. J Neuroinflammation. 2014;11:4.
42. El-Ansary A, Al-Ayadhi L. Neuroinflammation in autism spectrum disorders J Neuroinflammation. 2012;9.

43. El-Ansary A, Al-Ayadhi L. Lipid mediators in plasma of autism spectrum disorders. Lipids Health Dis. 2012;11:160.

44. Tomova A, Husarova V, Lakatosova S, Bakos J, Vlkova B, Babinska K, Ostatnikova D. Gastrointestinal microbiota in children with autism in Slovakia. Physiol Behav. 2015;138:179-87.

45. Cheng N, Ren N, Gao H, Lei XS, Zheng J, Cao W. Antioxidant and hepatoprotectiveeffectsofSchisandrachinensis pollen extract on $\mathrm{CCl} 4$ induced acute liver damage in mice. Food Chem Toxicol. 2013;55:234-40.

46. Eraslan G, Kanbu M, Silici S, Liman B, Altinordulu S, Sarica SZ. Evaluation of protective effect of bee pollen against propoxur toxicity in rat. Ecotoxicol Environ Saf. 2009;7(23):931-7.

47. Choi EM. Antinociceptive and antiinflammatory activities of pine (Pinusdensiflora) pollen extract. Phytother Res. 2007;21(5):471-5.

48. Lopez-Ramirez MA, Fischer R, Torres-Badillo CC, Davies HA, Logan K, Pfizenmaier K, Male DK, Sharrack B, Romero IA. Role of caspases in cytokineinduced barrier breakdown in human brain endothelial cells. J Immunol. 2012;189(6):3130-9.

49. Zweig MH, Campbell G. Receiver-operating characteristic (ROC) plots: a fundamental evaluation tool in clinical medicine. Clin Chem. 1993;39:561-77.

\section{Submit your next manuscript to BioMed Central and we will help you at every step:}

- We accept pre-submission inquiries

- Our selector tool helps you to find the most relevant journal

- We provide round the clock customer support

- Convenient online submission

- Thorough peer review

- Inclusion in PubMed and all major indexing services

- Maximum visibility for your research

Submit your manuscript at www.biomedcentral.com/submit
) Biomed Central 